\title{
Evaluating the social impact of youth digital culture co-creation: let's participate and play.
}

\author{
Alicja Pawluczuk \\ Edinburgh Napier \\ University \\ United Kingdom \\ a.pawluczuk@napier.ac.uk
}

\author{
Gemma Webster \\ Edinburgh Napier \\ University \\ United Kingdom \\ g.webster@napier.ac.uk
}

\author{
Colin Smith \\ Edinburgh Napier \\ University \\ United Kingdom \\ c.smith@napier.ac.uk
}

\author{
Hazel Hall \\ Edinburgh Napier \\ University \\ United Kingdom \\ h.hall@napier.ac.uk
}

\begin{abstract}
This paper examines young people's participation in digital culture and current approaches to measure its social impact. The analysis of the literature presented here reveals current scholarly understanding of the value of digital youth culture, social impact evaluation methods and their limitations. In order to contribute to the analysis of the value of young people's contribution to digital culture, this paper proposes two areas of consideration when working with young people: 1) Youth participation in evaluation; 2) Playful approaches to evaluation.
\end{abstract}

Digital Youth, Youth, Digital Culture, Social Impact, Social Impact Evaluation, Evaluation

\section{INTRODUCTION}

Defined as "innovators and drivers of new media change" (Buckingham, 2008), young people are currently the co-creators of digital culture. This prominence of digital media in young people's lives has been recognised in the field of youth participation, both in the United Kingdom and worldwide (Adobe Youth Voices, 2017, Young Scot, 2017; Time to Shine Digital, 2015; STEP, 2016). Consequently, in the $21^{\text {st }}$ century, youth-centered organisations have recognised digital literacy and digital creativity as core elements of their work with youth (LGBT Youth Scotland, 2017; United Nations, 2015). Likewise, in the academic literature, youth digital culture has been recognised as a source of inspiration and empowerment (Black, Castro \& Lin, 2015).

However, since digital media have become core elements of young people's everyday lives, youth development practitioners (for example Wilson, 2017; \#NotWithoutMe, 2017) and researchers (Buckingham, 2008; Erstad, 2012; Livingstone, 2012) have struggled to find ways to holistically examine and measure the social impact of young people's participation in digital culture. A literature review reveals that there are currently no evaluation frameworks to specifically measure the social impact of youth digital cultural projects. (Buckingham, 2008; Erstad, 2012; Livingstone, 2012).
The aim of this paper is to examine research gap in the social impact evaluation of digital youth culture co-creation. The analysis of the literature presented here reveals current scholarly understandings of the value of digital youth culture and its limitations. This paper proposes two areas of consideration when working with young people:

(i) Youth participation in evaluation

(ii) Playful approaches to evaluation

This paper describes the above areas so that they can contribute to discussions about how digital and $\mathrm{HCl}$ scholars and practitioners might better enable young people to participate in the social impact evaluation processes. The analysis presented here has been gathered from secondary sources, as a part of a doctoral research project's literature review

\section{TERMINOLOGY}

While a variety of definitions of the term digital culture have been suggested, this paper adopts that of Deuze, who saw it as "an emerging set of values, practices, and expectations the way people (should) act and interact with the contemporary networked society" (Deuze, 2006, p.63). Deuze (2006) has defined digital culture as a participatory and collaborative system of practices, which enable users to co-create, remix and re-use cultural content. In the context of this study, young people 
are perceived as active participants and co-creators of digital culture.

Additionally, the following understanding of social impact is suggested: 'all social and cultural consequences to human populations of any public or private actions that alter the ways in which people live, work, play, relate to another, organise to meet their needs, and generally cope as members of society' (Burdge \& Vanclay 1995, p.59). This doctoral research project considers young people as being individuals aged 16 to 25 years old.

\section{YOUTH AND DIGITAL CULTURE: SOCIAL IMPACT IN THE LITERATURE}

Since the early 2000 s, youth development practice has been profoundly influenced with the invention of the digital culture, shaped by "interactive, convergent, and networked media" (Livingstone, 2012 , p.1). Scholars have frequently discussed the positive and negative aspects of youth participation in digital culture (Black et al., 2015; Buckingham, 2008; Erstad, 2012; Livingstone, 2012; Livingstone \& Sefton-Green, 2016).

\subsection{Positive impact}

The digital age has provided young people with new opportunities to co-create and share ideas, learn and shape their identities (Ito et.al, 2013). Young digital citizens have embraced mediated tools to establish, communicate, and understand their interactions with society (Robards \& Bennet, 2014). Digital youth culture and its interactive and inclusive nature, have allowed young people to contribute towards positive social change (Buckingham, 2008).

Elsewhere, the digital culture has been described as 'a force of liberation' (Buckingham, 2008, p.12), saving education from its oppressive and formal environment (Black et al., 2015). Indeed, digital media have provided youth with opportunities for self-directed learning, experimentation, and networking (Black et al., 2015; Ito et al., 2008). Through their work, young digital storytellers, artists, and activists (Adobe Youth Voivce, 2017; UNCTAD Youth Network, 2017) have frequently contributed youth's perspectives on issues such as global warming, equal rights and poverty. It can be argued that this generation of self-driven digital makers has not only largely contributed towards the creation of digital culture, but also to societal transformations of the digital age.

\subsection{Negative impact}

Negative implications of youth digital culture cocreation have also been examined in the literature (for example Buckingham, 2008; Herring, 2007; Livingstone, Mascheroni \& Staksrud, 2015). Firstly, it has been claimed that it is necessary not to 'romanticize' about the liberating potential of digital youth culture (Buckingham, 2008). Although digital media provide young people with new spaces to express their views, it is in fact the previous generations that capitalize on and moderate media (Herring, 2007). Herring (2007) has described this as a sense of "illusionary freedom and autonomy" where adults manage youth's digital experiences (2007, p.72). Elsewhere, the discussion on problems of privacy, peer-pressure, and selfrepresentation have been highlighted as possible sources of negative impact on young digital citizens (Livingstone, Mascheroni \& Staksrud, 2015). For example, a recent report published by the National Society for the Prevention of Cruelty to Children (Bentley, O'Hagan, Raff \& Bhatti, 2016), has noted that counselling support related to young people's online activity has increased, with cyber bullying related support increasing by 13 per cent between 2014-2016, and 15 per cent increase related to sexting in years 2014-2016 (Bentley et al., 2016, p.41).

\section{RESEARCH GAP: DIGITAL CULTURE CO- CREATION AND SOCIAL IMPACT EVALUATION}

Despite numerous claims on the value of digital youth culture co-creation, both positive and negative, the literature fails to address the notion of social impact evaluation of youth digital culture cocreation (Buccieri \& Molleson, 2015; Livingstone, Makril \& Ebsem 2017; Mascheroni \& Staksrud, 2015).

"There is "a wealth of information about children's
technology and the design process to create it,
there is a dearth of information regarding how the
children who participate in these design
processes may be affected by their participation"
(Guha et al., 2010, p.198).

Livingstone et al. have claimed that it is not yet clear how "online opportunities may (or may not) result in tangible benefits" (2015, p.14) to younger generations. Examining the use digital technologies in youth social work, Mackril \& Ebsen have claimed "there is still limited research on how to assess the impact of digital technologies" on youth work (2017, p.1). Elsewhere, Ito et al. have argued that measuring outcomes of youth digital participatory initiatives proves to be an unanswered question (2013, p.46). Likewise, in a practice-based context, a recent UK based digital youth inclusion project outlined social impact evaluation as key challenges:

"Let's acknowledge that measuring the impact in learning digital skills is tough!!" (\#NotWithoutMe, 2017).

Equally, in the field of $\mathrm{HCl}$, social impact evaluation has been highlighted as a problematic and yet unexplored concept (Balestrini, Rogers \& Marshall, 
2015; Guha, Druin \& Fails, 2010). Here, young people have been increasingly collaborating in digital participatory settings (Fitton et al., 2016). However, despite extensive research concerned with collaborative and co-creative approaches in digital design, it has been claimed that "these works do not explore the impact the process has on its participants, and rather focus on the process itself" (Guha et al., 2010, p.199). Additionally, it has been argued that it is essential to address the lack of "methods to assess the social impact of the resulting technologies and emerged practices" (Balestrini et al., 2015, p. 35).

\section{YOUTH DIGITAL CULTURE CO-CREATION AND SOCIAL IMPACT EVALUATION: LET'S PARTICIPATE AND PLAY}

Analysing literature in the areas of social impact evaluation (Checkoway \& Richards-Schuster, 2003; Gawler, 2005; Sabo, 2003; Walker,2007) and youth digital culture (Hyder, 2017; Livingstone, Mascheroni \& Staksrud 2015) has identified two areas for consideration when evaluating with youth: youth participation and play.

\subsection{Let's participate}

Both youth development scholars (Checkoway \& Richards-Schuster, 2003; Gawler, 2005; Sabo, 2003; Walker,2007) and digital youth practitioners (\#NotWithoutMe, 2017) have agreed that young people should play active roles in the evaluation process. However, many of the evaluation approaches currently used offer limited input from young people. For example, the literature review reveals that most scholars have adopted functionalbut traditional- research approaches when measuring the impact of youth digital culture cocreation (Hyder, 2017; Livingstone, Mascheroni \& Staksrud 2015). Tools such as surveys and interviews (Quinlan 2015; Stevens, GilliardMatthews, Dunaev, Woods \& Brawner, 2016), case studies (Hyder, 2017), and/or ethnographic observations (Ito et al. 2008; Livingstone \& SeftonGreen 2016) have been applied to date. Indeed, these methods provide relevant information regarding the social impact of youth digital culture co-creation. However, a question needs to be asked, to what extent can traditional evaluation methods represent young people's voices?

\footnotetext{
"It's about whose definition of impact, an aspiration, a value and a fact is considered legitimate and whose is dismissed as subjective, emotional and irrelevant" (Lockie, 2001, p.279).
}

Social impact evaluation scholars for example Adam \& Garbutt, 2008; Lockie, 2001) and digital youth practitioners (\#NotWithoutMe, 2017). have acknowledged that externally imposed methods can lead to limited or distracted version of social impact. Frequently, the purpose of social impact analysis has been described as a 'box-ticking' exercise, which primary function is to meets pre-agreed funding criteria (Adam \& Garbutt, 2008). Reviewed literature also reveals that historically traditional impact analysis methods have been linked to low success rate (Pant, 2015). The use of technocratic evaluation approaches has been critiqued for primarily "pre-empting the outcomes" (Lockie, 2001, p.281) and addressing funding criteria (Adams \& Garbutt, 2008).
"Young people have important perspectives, especially in the evalaution programs that serve them" (Checkoway \& Richards-Schuster, 2003, p.23).

Reviewed literature has highlighted a clear correlation between effective evaluation processes and participatory approaches (Lockie, 2001, p.278). One of the core values of the social impact analysis community states that "people have a right to be involved in the decision making about the planned interventions that will affect their lives (Vanclay, 2002, p.7). It has been argued that a community's participation must be recognised as a vital element of social impact evaluation process (Adams \& Garbutt, 2008).

Likewise, digital youth practitioners argue that it is essential to consider young digital participants as co-creators of the evaluation process and "ask young people what they want to learn/achieve. This will guide our evaluation/measuring success" (\#NotWithoutMe, 2017). The ongoing involvement in the evaluation process has also been outlined as a democratic and empowering process (Checkoway \& Richard-Schuster, 2003; Gawler, 2005; Sabo, 2003; Walker,2007). In a collaborative evaluation setting, youth and adults can work in equal partnership, where unique evaluation questions and methods can be created (Checkoway \& Richard-Schuster, 2003).

Thus, it can be argued that participatory youth evaluation approaches can be particularly useful in youth digital participatory context. As digital innovations continue to influence cultural and social norms (Livingstone, 2015), it is increasingly difficult for scholars and practitioners to keep up with the latest developments in digital youth culture (Buckingham, 2008). Therefore, considering young digital co-creators' expertise and unique perspectives at all stages of the evaluation process could enhance the quality of the process itself. As suggested by digital youth practitioners, it is essential to "involve young people in agreeing success criteria, which they can reflect on" (\#NotWithoutMe, 2017). 
Finally, implementing participatory elements into evaluation processes can also benefit the project facilitators and evaluation staff. Direct involvement and feedback from young participants can generate data which can change or improve digital projects in the future (Sabo Flores, 2008). Including young voices into the process can provide more valid and reliable results, which could contribute to a better and more holistic understanding of social impact (Walker, 2007).

\subsection{Let's play}

The idea of play has been a common thread in discussions about digital youth culture (Buckingham, 2008; Herring, 2007; Livingstone et a., 2002) and social impact evaluation (Gawler, 2005; Sabo, 2003).

\begin{abstract}
"Participatory evaluation projects support youth to create environments in which they could play with their identities rather than be defined by them" (Sabo, 2003, p.22).
\end{abstract}

The notions of play and interactivity, have also been examined in the context of youth-led social impact evaluation (Gawler, 2005; Sabo, 2003). Here, scholars have emphasised the importance of the "improvised evaluation roles" adapted by young people during the analysis (Sabo, 2003). For example, Sabo claims that through active engagement and play young people are able to "break out of their socially fixed identities" (2003, p.2003). Therefore, through acting out the roles of evaluation experts, young people are not only "performing a head taller" but are able to escape from the traditional and top-down hierarchy between the evaluator and the evaluated subject (Sabo, 2003). It can be argued that this act of 'makebelieve' (Turner, 2016), might enable youth's liberation from the oppressive power dynamics imposed on them by societal norms.

\footnotetext{
"Creating playful environments allows people to move in and around issues to learn in new and unique ways" (Flores, 2007, p.25).
}

Play provides young people with opportunities to discover and design innovative ideas and solutions (Thomas \& Brown, 2011). Ensured that 'not knowing is OK', young participants can discover and test new ideas and solutions (Flores, 2007). Thus, playful evaluation methods can further enhance participants learning and provide opportunities to create unique and age-appropriate evaluation tools (Gawler, 2005). Scholars have advocated for the use of more playful and collaborative tools to analyse social impact to enhance young people's personal and social development (Checkoway \& Richards-Schister, 2003).

"Playing with evaluation concepts and methods helps level the playing field so that staff and youth can begin to see evaluation as something everyone can do" (Flores, 2007, p25).

Finally, implementing playfulness into evaluation can also benefit the project facilitators and evaluation staff. Participating in an equal and creative dialogue, all project stakeholders provides opportunities to co-create a shared understanding of social impact (Cousin \& Whitmore, 1998). This cocreation of meaning can be important when trying to address the research gap in the areas of digital youth culture co-creation and social impact evaluation.

\section{CONCLUSION}

Current scholarly discussion on digital youth culture co-creation and approaches to evaluate the social impact of such initiatives have been examined in this paper. The analysis highlights the existing understandings of social impact of youth digital culture, and addresses positive and negative impact. Additionally, this paper has drawn the discussion on the importance of both participation and play in evaluation approaches.

"There is no single tool or methods that can capture the whole range of impacts or that can be applied by all organisations" (Maas \& Liket, 2011, p.9).

This literature review has highlighted two key areas for consideration while evaluating digital youth culture initiatives (5.1 and 5.2). Acknowledging that there is no single solution to this problem, this paper has proposed two areas for further consideration: youth participation in evaluation processes and playful approach to these processes. Although it seems that participatory and playful methods might improve the understanding of social impact of youth digital culture co-creation, it is important to note that participatory evaluation is not without challenges. For example, the notions of power, ethics, participant selection, and technical expertise should be investigated further. There is, therefore, a definite need for future research on evaluating the social impacts of digital youth culture.

\section{FUTURE RESEARCH PLAN FOR THIS DOCTORAL STUDY}

The future steps for this doctoral research project are as follows:

1) to examine the relevance of youth participatory evaluation among scholars and digital youth practitioners;

2) to work with young people as co-researchers in participatory evaluation settings to learn about their experience of the evaluation process and views on social impact. 
This will be achieved with an implementation of sequential mixed methods such as open ended interviews, surveys, and youth participatory action research workshops. The final results of this study will be available in 2019/20.

\section{REFERENCES}

Adobe Youth Voices. (n.d.). Retrieved June 2, 2017, from http://www.adobe.com/uk/corporateresponsibility/education/adobe-youth-voices.html

Balestrini, M., Rogers, Y., \& Marshall, P. (2015, July). Civically engaged $\mathrm{HCl}$ : tensions between novelty and social impact. In Proceedings of the 2015 British HCl Conference (pp. 35-36). ACM.

Bentley, H., O'Hagan, O., Raff, A., \& Bhatti, I. (2016). How safe are our children?. Overview of Child Protection in the UK. London: NSPCC.

Black, J., Castro, J., \& Lin, C. (2015). Youth practices in digital arts and new media: Learning in formal and informal settings. Springer.

Boyd, D. (2014). It's complicated: The social lives of networked teens. Yale University Press.

Buccieri, K., \& Molleson, G. (2015). Empowering Homeless Youth: Building Capacity through the Development of Mobile Technology. Journal of Community Practice, 23(2), 238-254.

Buckingham, D. (2008). Youth, Identity, and Digital Media. London: MIT press.

Burdge, R. J., \& Vanclay, F. (1995). Social impact assessment. Environmental and social impact assessment, 31-65.

Cammarota, J., \& Fine, M. (2008). Revolutionizing education: Youth participatory action research in motion. New York, NY: Routledge.

Checkoway, B., \& Richards-Schuster, K. (2003). Youth participation in community evaluation research. American Journal of Evaluation, 24(1), 21-33.

Checkoway, B. N., \& Gutierrez, L. M. (2006). Youth participation and community change: An introduction. Journal of community practice, 14(12), 1-9.

Deuze, M. (2006). Participation, remediation, bricolage: Considering principal components of a digital culture. The information society, 22(2), 6375.

Erstad, O. (2012). The learning lives of digital youth-beyond the formal and informal. Oxford Review of Education, 38(1), 25-43.

Fitton, D., Bell, B. T., Little, L., Horton, M., Read, J. C., Rouse, M., \& Toth, N. (2016). Working with Teenagers in $\mathrm{HCl}$ Research: A Reflection on
Techniques Used in the Taking on the Teenagers Project. In Perspectives on $\mathrm{HCl}$ Research with Teenagers (pp. 237-267). Springer International Publishing.

Flores, K. S. (2007). Youth participatory evaluation: Strategies for engaging young people (Vol. 14). John Wiley \& Sons.

Flores, K. S. (2007). Youth participatory evaluation: Strategies for engaging young people(Vol. 14). John Wiley \& Sons.

Gawler, M. (2005). Useful tools for engaging young people in participatory evaluation. CEE/CIS Regional Office: UNICEF.

Guha, M. L., Druin, A., \& Fails, J. A. (2010, June). Investigating the impact of design processes on children. In Proceedings of the 9th International Conference on Interaction Design and Children(pp. 198-201). ACM.

Hart, R. A. (1997). Children's Participation. From Tokenism to Citizenship. Inocennti Essays, 4-20.

Herring, S. C. (2008). Questioning the generational divide: Technological exoticism and adult constructions of online youth identity. Youth, identity, and digital media, 71-94.

Hyder, Nadia. Evaluation of TTS.Digital. Rep. Research Scotland, 2017. Web.

Ito, M., Gutiérrez, K., Livingstone, S., Penuel, B., Rhodes, J., Salen, K., ... \& Watkins, S. C. (2013). Connected learning: An agenda for research and design. BookBaby.

Ito, M., Horst, H. A., Bittanti, M., Stephenson, B. H., Lange, P. G., Pascoe, C. J., ... \& Martínez, K. Z. (2009). Living and learning with new media: Summary of findings from the Digital Youth Project. MIT Press.

Livingstone, S. (2012). Critical reflections on the benefits of ICT in education. Oxford review of education, 38(1), 9-24.

Livingstone, S., \& Sefton-Green, J. (2016). The class: Living and learning in the digital age. NYU Press.

Livingstone, S., Mascheroni, G., \& Staksrud, E. (2015). Developing a framework for researching children's online risks and opportunities in Europe.

Maas, K., \& Liket, K. (2011). Social impact measurement: Classification of methods. In Environmental management accounting and supply chain management (pp. 171-202). Springer Netherlands.

Mackrill, T., \& Ebsen, F. (2017). Key misconceptions when assessing digital technology for municipal youth social work. European Journal of Social Work, 1-12. 
\#NotWithoutMe. Supporting Digital Inclusion for All Young People. Dunfermline: Carniege Trust, Mar. 2017. Word document.

Percy-Smith, B., \& Thomas, N. (Eds.). (2009). A handbook of children and young people's participation: Perspectives from theory and practice. Routledge.

Quinlan, O. (2015). Young Digital Makers. London: Nesta.

Robards, B., \& Bennett, A. (2011). MyTribe: Postsubcultural manifestations of belonging on social network sites. Sociology, 45(2), 303-317.

Sabo, K. (2003). A Vygotskian perspective on youth participatory evaluation. New directions for evaluation, 2003(98), 13-24.

STEP. Scottish Travel Education Programme, 2016. Web. 30 Mar. 2017.

Stevens, R., Gilliard-Matthews, S., Dunaev, J., Woods, M. K., \& Brawner, B. M. (2016). The digital hood: Social media use among youth in disadvantaged neighborhoods. new media \& society, 1461444815625941.Chicago

Stevens, R., Gilliard-Matthews, S., Dunaev, J., Woods, M. K., \& Brawner, B. M. (2016). The digital hood: Social media use among youth in disadvantaged neighborhoods. new media \& society, $\quad$ 1461444815625941.Chicago

TTS.Digital. Creative Scotland, 2015. Web. 30 Mar. 2017.

Turner, P., \& Harviainen, J. T. (Eds.). (2016). Digital Make-Believe. Springer International Publishing.

UNCTAD Youth Network. (n.d.). Retrieved June 2, 2017, from http://unctad.org/en/Pages/YouthNetwork.aspx

Young Scot Digital Academy. (2015). Retrieved March 30, 2017, from http://www.youngscot.net/what-wedo/digital-academy/ 